\title{
How to solve the problem of phenomenal unity: finding alternatives to the single state conception
}

\author{
Wanja Wiese ${ }^{1}$ (D)
}

Published online: 2 September 2016

(C) The Author(s) 2016. This article is published with open access at Springerlink.com

\begin{abstract}
The problem of phenomenal unity (PPU) consists in providing a phenomenological characterization of the difference between phenomenally unified and disunified conscious experiences. Potential solutions to PPU are faced with an important challenge (which Tim Bayne calls the "explanatory regress objection"). I show that this challenge can be conceived as a phenomenological dual to what is known as Bradley's regress. This perspective (i) facilitates progress on PPU by finding duals to possible solutions to Bradley's regress and (ii) makes it intelligible why many characterize phenomenal unity in terms of the existence of a single global conscious state. I call this latter view the "single state conception" (SSC). SSC is superficially attractive, because it seems to provide a solution to the phenomenological dual to Bradley's regress, but should still be rejected, because (1) it does not solve PPU; (2) instead, it creates more problems; (3) these problems can be avoided by alternative conceptions of phenomenal unity.
\end{abstract}

Keywords Bradley's regress $\cdot$ Consciousness $\cdot$ Phenomenal unity S Single state conception

Phenomenal unity is typically characterized only loosely, as "experiencing things together" (cf. Baumann 2007), or by pointing to a "conjoint phenomenology" (cf. Bayne \& Chalmers 2003). These descriptions are then often analyzed in terms of the existence of a single conscious state. ${ }^{1}$ Here, I

${ }^{1}$ I use the terms "conscious state", "phenomenal state", and "conscious experience" interchangeably in this paper.

Wanja Wiese

wawiese@uni-mainz.de

1 Department of Philosophy, Johannes Gutenberg University, 55099 Mainz, Germany 
argue that a convincing account of phenomenal unity must do better than that, and suggest how to do it.

The plan of this paper is the following. First, I provide a basic clarification: phenomenal unity is a relation, so we need to say something about the scope of this relation. I propose to conceive of phenomenal unity as a relation $R_{P U}$ between phenomenal properties (instantiated by an organism at a time; section 1). Regarding the problem of phenomenal unity (PPU), we can then distinguish two aspects: the first is phenomenological, the second empirical (see section 2). The phenomenological aspect can be formulated as follows: how can we characterize $\mathrm{R}_{\mathrm{PU}}$ in conceptually clear and coherent ways? This points to possible solutions to PPU. The empirical aspect is to find out which of these possibilities are realized in the case of (neurotypical) human beings, and how. Having defined the problem, I next discuss a problem which Tim Bayne calls the explanatory regress objection (cf. Bayne 2005). As I shall show, this objection can be construed as a phenomenological dual to what is known as Bradley's regress (cf. Bradley 1969[1893]). Hence, possible solutions to Bradley's regress can be drawn upon in order to inspire possible solutions to PPU (section 3). Such solutions should be taken seriously as alternatives to what I call the single state conception (SSC; section 4). Although this conception is extremely popular, it does not solve PPU, as I will show in section 5. After that, I shall analyze why PPU is such a difficult problem (section 6). This diagnosis, together with the possible solutions I sketch in this paper, as well as the conceptual link to Bradley's regress, will point to promising paths for future research on PPU.

\section{Basic conceptual considerations}

Before we can formulate the problem of phenomenal unity, we have to define the scope of this unity relation. I shall define phenomenal unity as a relation on the set of all phenomenal properties that characterize what a single conscious organism is experiencing at a given time. I will explain and defend this basic characterization of phenomenal unity below.

\subsection{Phenomenal versus logical subjects of experience}

When people say that consciousness displays unity, they do not mean that we all share a single conscious experience. My conscious experience is not unified with your conscious experience. However, my conscious experience is unified, and, I presume, your conscious experience is unified, as well. In other words, phenomenal unity typically holds for single subjects of experience. But what is a subject of experience?

Here, we need to avoid a first potential pitfall. One possible answer to the question posed above is that I experience myself as a subject of experience. $I$ am consciously experiencing a rainbow right now, $I$ am experiencing the smell of sandalwood. The "I" in these descriptions refers to what I shall call a phenomenal subject of experience. It is tempting to define phenomenal unity with respect to phenomenal subjects ("Everything $I$ am experiencing is phenomenally unified." or "My conscious experience is phenomenally unified."). However, this raises the question of what exactly a phenomenal subject is and 
whether consciousness necessarily displays phenomenal subjecthood (there may be conscious creatures that do not experience themselves as subjects of experience, cf. Metzinger 2004[2003], pp. 157, 568). What is more, it seems that defining phenomenal unity in terms of phenomenal subjects presupposes unity of the phenomenal subject (cf. Prinz 2012, pp. 244 f.). And since the phenomenal subject is experientially manifest, the unity of the subject seems to be experientially manifest, as well. Hence, it seems that unity of the phenomenal subject is another type of phenomenal unity (i.e., it is an experientially manifest unity), but this is not obviously what most people mean when they talk about phenomenal unity. While one could claim that phenomenal unity just is the problem of phenomenal subject unity, this would not be a neutral way of formulating the problem: it is the view that phenomenal unity is not a distinct phenomenon, but that it can be identified with phenomenal subject unity. Making a substantial claim when all that is asked for is a formulation of the problem is certainly not the best way to proceed.

A different way to interpret the question "What is the subject of experience?" is in terms of the entities to which we ascribe conscious experiences. And here it is plausible to say that we ascribe conscious experiences to organisms (cf. Bayne 2010, p. 9, and Prinz 2012, pp. 244 f.). When a conscious creature (behaviorally) indicates that it is consciously experiencing X (e.g., that it is seeing a red dot or hearing a certain sound), we can say that the creature is conscious of $\mathrm{X}$ without presupposing that the creature experiences itself as being a subject of experience. In other words, we do not have to presuppose any substantial position regarding phenomenal subjects whatsoever. ${ }^{2}$ I shall call a (conscious) organism the logical subject of experience (to distinguish it from the phenomenal subject; Williford 2015, draws the same distinction, using the terms "phenomenological subject" and "metaphysical subject").

\subsection{Phenomenal properties are the relata of the phenomenal unity relation}

Let us denote the phenomenal unity relation with $\mathrm{R}_{\mathrm{PU}}$. What are the relata of this relation? Typically, characterizations of phenomenal unity refer to contents of consciousness (this is especially explicit in Tye 2003) or to "what it's like" to have certain experiences (cf. Bayne \& Chalmers 2003):

Specifically, phenomenal unity is a matter of simultaneously experienced perceptual qualities entering into the same phenomenal content. (Tye 2003, p. 36)

We can say that two conscious states are subsumptively phenomenally unified (or simply phenomenally unified) if there is something it is like for a subject to be in both states simultaneously. (Bayne \& Chalmers 2003, p. 32)

\footnotetext{
${ }^{2}$ Of course, if we want to specify exactly what the creature is experiencing and whether everything it is experiencing is unified, we have to face the problem of phenomenal subjecthood and determine whether the creature is self-aware in this sense. But as long as we only want to define the problem of phenomenal unity, this can be avoided.
} 
What it is like to be in a certain conscious state is determined by the phenomenal properties that are currently instantiated. Although phenomenal properties are not obviously identical to phenomenal contents, I shall nevertheless stipulate that the relata of the phenomenal unity relation are instantiations of phenomenal properties (representationalists can interpret phenomenal properties as the contents of phenomenal representations; see e.g., Metzinger 2004[2003]; Tye 2003). This is relatively uncontroversial.

A further non-controversial point is that we can conceive of $\mathrm{R}_{\mathrm{PU}}$ not only as a two-place relation, but also as an $n$-place relation. This means that not only any pairs of phenomenal properties that (partly) characterize what a subject is experiencing can be phenomenally unified; if a subject's experience displays three or more distinct phenomenal properties, then those can also be unified (this is reflected in what Bayne and Chalmers 2003, p. 33, call the "Pairwise Phenomenal Unity Thesis" and the "Total Phenomenal Unity Thesis", respectively).

A slightly more controversial question is whether unified phenomenal properties are unified in virtue of a further phenomenal property (e.g., a "phenomenal glue"). Tye (2003) argues that this leads to a vicious regress:

If unity of experiences is itself experienced, then for two unified experiences, there must in addition be an experience of unity which must in turn also be unified with the other experiences, leading to another experience of unity which must again be unified etc. (Tye 2003, pp. 21 f.)

So the problem is: if two distinct phenomenal properties $F$ and $G$ are instantiated at the same time by the same subject, and if their unity goes along with a third phenomenal property $\mathrm{H}$, it stands to question whether $\mathrm{H}$ is unified with $\mathrm{F}$ and $\mathrm{G}$. If it is, there needs to be a fourth phenomenal property connecting them, and so on. It therefore seems that no conscious experience can ever be completely unified, because there will always be at least one phenomenal property that is not unified with all other phenomenal properties. This problem (which Tim Bayne has called the "explanatory regress objection", see Bayne 2005) is formally similar to what is known as Bradley's regress in metaphysics (cf. Bradley 1969[1893], pp. 27 f.), so I shall call this problem the phenomenological Bradley (PB). In section 3, I will make this similarity explicit.

There are two principled ways in which one can deal with PB. The first is to deny that $\mathrm{R}_{\mathrm{PU}}$ is experientially manifest. When two or more phenomenal properties are phenomenally unified, this unity will then fail to go along with a phenomenal difference. The problem of phenomenal unity would thus be a purely metaphysical or ontological problem. This path is pursued in Tye (2003). The second option is to take PB as a challenge. Any account of phenomenal unity (according to which $\mathrm{R}_{\mathrm{PU}}$ is experientially manifest) has to show how $\mathrm{PB}$ can be avoided (or why the regress is not vicious).

Here, I will assume that PB should not be seen as a reason to reject the view that phenomenal unity is experientially manifest (hence the term "phenomenal unity"). Instead, I will discuss different ways in which the phenomenological 
Bradley can be solved (in section 3). But we still have to define the problem of phenomenal unity.

\subsection{Phenomenally unified properties can correspond to experienced successions of events}

So far, we have defined phenomenal unity $\left(\mathrm{R}_{\mathrm{PU}}\right)$ as a relation between phenomenal properties instantiated by a single organism (i.e., by a single logical subject). Since conscious organisms remain the same over time, but their conscious experiences change, we have to restrict the temporal scope of $\mathrm{R}_{\mathrm{PU}}$. If we seek to define synchronic phenomenal unity, it seems we have to confine $\mathrm{R}_{\mathrm{PU}}$ to phenomenal properties instantiated "at the same time".

Events that are happening right now can be experienced together; by contrast, I do not experience an event happening now together with an event I observed last week (at most, I experience a vivid memory of that event together with the event that is happening now; but that memory is distinct from the experience I had last week). So in defining phenomenal unity, we have to specify what "right now" or "at the same time" means.

One obvious option is to say that only simultaneously instantiated phenomenal properties can be phenomenally unified. However, things get complicated here. Say my experience of two events $E_{1}$ and $E_{2}$ is characterized by corresponding phenomenal properties $P_{1}$ and $P_{2}$. When the two events occur simultaneously, I will usually experience the events as simultaneous, and hence it makes sense to assume that the corresponding phenomenal properties are instantiated at the same time. But nonsimultaneous events (that are also experienced as non-simultaneous) can be experienced together, as well. A simple example is apparent motion: two stimuli, two discs, say, are flashed in close succession, but instead of experiencing two isolated events (one disc flashes here, the other there), one experiences a single moving disc (moving from the location of the first disc to the location of the second disc). Apparent motion can thus serve to illustrate the idea that non-simultaneous events (that are also experienced as non-simultaneous) can still be experienced together. Is this experienced togetherness different from the simultaneous case (in which events that are experienced together are experienced as simultaneous)? Put differently: If $E_{1}$ and $E_{2}$ occur simultaneously, and are experienced as simultaneous, it makes sense to assume that the corresponding phenomenal properties $P_{1}$ and $P_{2}$ are simultaneously instantiated, too. But if $E_{1}$ and $E_{2}$ are experienced together, without being experienced as simultaneous, does this mean that $P_{1}$ and $P_{2}$ are not simultaneously instantiated?

At first sight, one might be inclined to say that there is a difference between these cases: the first (in which events are experienced as simultaneous) is a case of synchronic unity, the second is a case of diachronic unity. However, I will argue that there are at least in-between-cases, for which the intuitive distinction between synchronic and diachronic phenomenal unity is dissolved. In such cases, it is unclear whether the main effect is due to purely synchronic phenomenal unity or diachronic unity. A good example is the sound-induced flash illusion. In this illusion, discovered by Shams et al. (2000), subjects are presented with a briefly flashed disc, along with a quick succession of beeps. Instead of reporting the occurrence of a single flash, subjects tend to report two flashes. What seems to happen is that the perception of the sounds 
influences how the flashing disc is perceived. Furthermore, since the disc is only briefly flashed, and the accompanying beeps are $57 \mathrm{~ms}$ apart, the visual and auditory stimuli are not strictly simultaneous. Hence, when we say that the visual and auditory events are experienced together (which is supported by the fact that the experience of one influences the other), this cannot simply be described as a case of synchronic unity. It is not a pure case of diachronic unity, either, because subjects experience the visual and auditory events at the same time (or, at least, they experience the visual event as occurring during the occurrence of the auditory events, not before or after it). Even more striking examples can be found in research on postdictive phenomena (cf. Eagleman \& Sejnowski 2000; Shimojo 2014). These phenomena show that the perception of an event can be influenced by events occurring 100 to $150 \mathrm{~ms}$ after the initial event. An example is the cutaneous rabbit illusion (Geldard \& Sherrick 1972). In this illusion, taps are delivered at three locations of the subject's arm: first, there are five taps near the wrist, then five taps close to the elbow, followed by five taps further up the arm. If the timing is right, subjects do not report a series of taps at three locations, but a more distributed sequence of taps, also at intermediate locations that have not actually been tapped (e.g., between wrist and elbow). So how the first five taps are experienced also depends on what happens after the occurrence of the first taps. For instance, if only the first five taps are delivered, subjects will report taps at a single location only. But if these taps are succeeded by further taps in the manner described above, subjects will report a series of taps that almost feel as if a rabbit was hopping up their arms (hence the name of the illusion).

Of course, one could say that postdictive phenomena are just examples of diachronic unity, and hence do not rule out the possibility that synchronic experiential togetherness is different from diachronic experiential togetherness. However, what such phenomena show is that there are cases in which we cannot consider experiences of simultaneous events without taking the temporal context into account. If two phenomenal properties $P_{1}$ and $P_{2}$ correspond to experiencing two simultaneous events $E_{1}$ and $E_{2}$, this also partly determines the temporal context in which $P_{1}$ and $P_{2}$ occur. If one of the events is the second tap at the wrist in the cutaneous rabbit paradigm, for instance, it cannot be matched with a particular phenomenal property unless we know what is happening afterwards (because this can influence how the tap is experienced, cf. Phillips 2014, p. 151). Again, this shows that there are situations in which one or more events can be experienced together with non-simultaneous events (which are also experienced as nonsimultaneous).

But it suggests even more, namely that we never experience events in temporal isolation, but always as part of a temporal context (even if that context comprises only a fraction of a second). In other words, at least in ordinary waking states, we always experience the passage of time (I briefly return to this point below, in section 3.2).

A possible objection to this view is that the above is only true as an epistemological claim: we cannot know about phenomenal properties instantiated during very short intervals (say, under $50 \mathrm{~ms}$ ), without taking a broader temporal context into account. Despite this, one could think, there is a metaphysical (or even physical) fact regarding which phenomenal property is instantiated when, say, the first and second taps are being delivered in the cutaneous rabbit experiment.

However, this misses the point. The above has not been a metaphysical, but a phenomenological point: when we experience something, we often experience it as part 
of a temporal context. For instance, when subjects are presented with apparent motion stimuli and report that they are experiencing a single dot moving from one location to another, this means they are experiencing two temporally separate events together. But even if we assume that the subject first experiences only a single, stationary, dot (but is unable to access and report this information shortly afterwards), postdictive phenomena suggest that this should not be described as experiencing a point-like event, but as experiencing a very short sequence (in which nothing happens, safe for a brieflyflashing dot). ${ }^{3}$ So if we want to keep the distinction between diachronic and synchronic phenomenal unity, we have to assume that there are at least some cases of synchronic unity which presuppose a form of diachronic unity. Generalizing from research on postdictive phenomena, one might even go so far as to claim that diachronic unity is always the more basic relation, because all cases of synchronic unity involve stretches of time with a "before" and an "after" (even if we just experience two simultaneous pointlike events in a void temporal context, i.e., even if we experience that nothing is happening before and after the occurrence of the two simultaneous events). However, I will not defend this stronger claim here, since I only need the weaker claim that some cases of synchronic unity presuppose diachronic unity. ${ }^{4}$

Summing up, we can say that $\mathrm{R}_{\mathrm{PU}}$ is a relation between phenomenal properties instantiated by a single conscious organism at a time. Crucially, "at a time" can also mean that those phenomenal properties correspond to experienced successions of events. So cases of "synchronic" phenomenal unity in which two or more events are experienced together also include cases in which the perceived events are not simultaneous.

\section{The problem of phenomenal unity (PPU)}

In this section, I will show how the problem of phenomenal unity (PPU) can be defined in a relatively neutral way, i.e., without making strong metaphysical assumptions regarding consciousness as such. In particular, we do not need individuation criteria for phenomenal states (or experiences), because PPU can be defined in terms of phenomenal properties. Recall how Bayne and Chalmers (2003) characterize phenomenal unity:

We can say that two conscious states are subsumptively phenomenally unified (or simply phenomenally unified) if there is something it is like for a subject to be in both states simultaneously. That is, two states are phenomenally unified when they have a conjoint phenomenology: a phenomenology of having both states at once that subsumes the phenomenology of the individual states. (Bayne $\&$ Chalmers 2003, p. 32)

\footnotetext{
${ }^{3}$ In other words, this treatment is neutral with respect to Stalinesque, Orwellian, or "Fame in the brain" interpretations of postdictive phenomena (for these notions, see Dennett 1991; Dennett \& Akins 2008; Dennett \& Kinsbourne 1992).

${ }^{4} \mathrm{I}$ am grateful to an anonymous reviewer for pointing this out. A version of the stronger position I am not defending here is proposed in Phillips (2011).
} 
An example of Bayne's in The Unity of Consciousness involves seeing a bartender and hearing a rumba:

There is something it is like to hear the rumba, there is something it is like to see the bartender work, and there is something it is like to hear the rumba while seeing the bartender work. (Bayne 2010, pp. 10 f.)

Obviously, phenomenal unity is something that is taken to change the phenomenal character of a conscious experience. It goes along with what I shall call "the phenomenal difference".

With the above, preliminary, characterization of $\mathrm{R}_{\mathrm{PU}}$ in hand, how can the problem of phenomenal unity be defined? According to Tim Bayne, the main problem is to formulate and defend a thesis about $\mathrm{R}_{\mathrm{PU}}$ that is substantial, plausible, and interesting (cf. Bayne 2010, p. 12). If we follow this approach, we have to argue if and to what extent consciousness is unified. However, this approach neglects a problem which, as I shall argue, needs to be solved first. This is the problem of providing a phenomenological characterization of $\mathrm{R}_{\mathrm{PU}}$. The characterization by Bayne and Chalmers (2003) cited above is not a phenomenological characterization in the sense intended here, because it just specifies that there is a "conjoint phenomenology", it only claims that phenomenal unity goes along with a phenomenal difference. But it does not specify what a conjoint phenomenology is (i.e., it leaves open what the phenomenal difference is). This is problematic because unless we know what the phenomenal difference is, we cannot even start to address the phenomenological Bradley (PB) (aka the explanatory regress objection).

Of course, one can also just ignore this problem, and claim that no phenomenological description of the phenomenal difference can be given. Barry Dainton, for instance, suggests:

That different and diverse experiences are experienced together as co-conscious is a basic fact about the experiential realm. Co-consciousness is a basic experiential relationship, one about which there is nothing more to be said, at least while we confine ourselves to describing how things seem. (Dainton 2000, p. 84)

The problem with such an approach is that it will not convince skeptics who believe that the presence of co-consciousness is not a basic fact about the experiential realm, or not a fact at all, because they are not convinced that there is such thing as phenomenal unity in the first place (at least if we assume that phenomenal unity goes along with a phenomenal difference). Recall from above that Tye (2003) claims that consciousness is synchronously unified, but that this unity does not go along with a phenomenal difference. Hill $(1991,2014)$ and Masrour (2014) argue that there is no such thing as global phenomenal unity; even though there are phenomenally manifest unity relations (like spatial, temporal, or causal unity), none of them connects everything a subject is experiencing at a time. Hence, we cannot take it for granted that there is a "conjoint phenomenology" that subsumes the phenomenology of all other phenomenal states (or phenomenal properties) a subject has at a time. 
Again, one option is to ignore skeptical voices and to presuppose that there is a global unity relation, even if we cannot say more about it. ${ }^{5}$ Here, I will suggest that we can do better. In what follows, I will argue that we can make progress on the problem of phenomenal unity (PPU), which I define as follows:

(1) Provide possible phenomenological characterizations of the phenomenal difference (between phenomenally unified and phenomenally disunified conscious experiences ${ }^{6}$ ).

(2) Provide analyses of these characterizations on subpersonal levels of description (like the computational, functional, or neurobiological level).

I shall call (1) the first problem of phenomenal unity (1PPU). A solution to this problem requires an account of unity from the 1st-person perspective. I shall call (2) the second problem of phenomenal unity (2PPU). In this paper, I will mainly be concerned with 1PPU. Solutions to 1PPU provide clear and coherent possibilities, 2PPU is necessary to find out which of them are actually realized in our case (and how).

In order to find possible solutions to 1PPU, it will be useful to consider the phenomenological dual to Bradley's regress (PB), as I will show in the next section. After that, I will discuss a common (mis)conception of phenomenal unity, the single state conception (SSC; section 4). In section 5, I will show why SSC can seem attractive (viz. because it seems to provide an elegant solution to $\mathrm{PB}$ ), and why it is nevertheless unfit to solve 1PPU. The main reason is that it does not clarify what the phenomenal difference is; even worse, it creates additional problems (and those problems can be avoided if we adopt alternative conceptions of $\left.\mathrm{R}_{\mathrm{PU}}\right)$.

\footnotetext{
${ }_{5}^{5}$ Another would be to claim that some persons, like Bayne, Chalmers, and Dainton, have conscious experiences displaying global phenomenal unity, while others, like Hill, Masrour, and Tye, do not. Consequently, one idea would be that introspective disputes cannot arise because if they stand in opposition, they are at most contrary or subcontrary phenomenological ascriptions. These phenomenological reports could then indicate that the phenomenologies might differ. This general strategy of avoiding introspective disputes has been suggested by Sascha Benjamin Fink (see Fink forthcoming 2016). I submit that this should only be the ultima ratio, if all attempts at solving the dispute have failed. This paper intends to make a contribution to solving the dispute, without supposing that some persons enjoy global phenomenal unity, while others do not. Apart from that, PPU remains even if it is the case that the extent to which conscious experience is phenomenally unified varies from person to person. As long as at least some persons enjoy globally phenomenally unified conscious experiences, we can ask what that means and how to describe the corresponding phenomenal difference.

${ }^{6}$ What do I mean by a conscious experience? Here, I follow Tim Bayne's (2010) tripartite account of phenomenal state individuation, according to which phenomenal states are individuated in terms of phenomenal properties instantiated by an organism at a time. Note that these phenomenal properties can also characterize how a subject is experiencing a succession of events (provided there is a sense in which those events are experienced together, cf. section 1.3 above). Furthermore, I am stipulating that what a subject is experiencing at a time always corresponds to a single conscious experience. Since I do not endorse the single state conception (see section 4), this should not be taken as a substantial claim, but as a definition of the term "conscious experience", and it does not entail that a subject's experience is thereby necessarily phenomenally unified (since I do not claim that consciousness is unified in virtue of the existence of a single global state, or vice versa). Furthermore, I do not take a stance regarding the question whether conscious experiences can have experiences as proper parts.
} 


\section{The phenomenological Bradley (PB)}

In this section, I shall first explain Bradley's regress, and then show how it can be reformulated as a challenge for solutions to 1PPU. This will yield a phenomenological dual to the regress problem. Possible solutions to the metaphysical version may then inspire possible solutions to the phenomenological variant.

\subsection{Bradley's regress and its phenomenological dual}

Maurin (2012) has recently published an extremely clear and succinct overview of Bradley's regress (which she calls the "Bradleyian regress", in order to emphasize that it does not presuppose all of Bradley's background assumptions, because they are not all essential to the problem itself) and possible solutions to it. Here, I will only briefly retrace her reconstruction of the argument, and the solutions she presents. As Maurin shows, the question from which the regress originates is: How can there be unity in complexity? She unpacks this in the following way: that there is complexity means that some state of affairs $\mathrm{F} a$ exists. This seems to entail that both the particular $a$ and the property F-ness exist, and that the proposition $<a$ is F $>$ is true. However, the mere existence of both F-ness and $a$ is not generally sufficient for this proposition to be true. It seems there must be some connection between F-ness and $a$ (unless either F-ness or $a$ are rigidly dependent upon the state of affairs $\mathrm{F}^{7}{ }^{7}$ also see below). But, whatever that connection is, it seems that this connection itself must also be connected to F-ness and $a$, and this is where the regress starts. More specifically, Maurin's reconstruction of Bradley's regress rests on the following premises:

(U'): There can be contingent unity in complexity. (2012, p. 796)

$\left(\mathrm{D}_{\text {truth }}\right)$ : If $<\mathrm{P}>$ and $<\mathrm{Q}>$ have different truth-conditions, then what reality must be like for $\langle$ P $>$ to be true is different from what it must be like for $\langle\mathrm{Q}>$ to be true. (ibid.)

$\left(\mathrm{D}_{\text {maker }}\right)$ : If $\mathrm{P}$ and $\mathrm{Q}$ are different, then something must make this difference. (2012, p. 797)

We can formulate a phenomenological dual of Bradley's regress (following Maurin's account). Here, the assumption is that there can be "phenomenal unity in phenomenal complexity", i.e., two distinct phenomenal properties $\mathrm{F}$ and $\mathrm{G}$ are instantiated, and they are related by $\mathrm{R}_{\mathrm{PU}}$. So not only F-ness and G-ness and the property of being related by $\mathrm{R}_{\mathrm{PU}}$ are instantiated (with respect to the same organism), but also the proposition $<\mathrm{R}_{\mathrm{PU}}(\mathrm{F}, \mathrm{G})>$ is true (this is what is meant by "phenomenal unity in phenomenal complexity" in what follows).

Note that there is a (superficial) difference between my definition of "phenomenal unity in complexity" and Maurin's definition of "unity in complexity": Maurin's definition involves a particular $a$ which has the property $\mathrm{F}$, so it might seem that an analogous phenomenological definition would have to involve a phenomenal property and a subject of experience. However, what is at issue in the phenomenological version is not how a subject can instantiate a phenomenal property, but how two (or more)

\footnotetext{
${ }^{7}$ I am grateful to an anonymous reviewer for suggesting to add this remark here.
} 
instantiated phenomenal properties can be related by $R_{P U}$ in such a way that there is a phenomenal difference. Furthermore, it is not even essential to the metaphysical version of the regress that it is formulated in terms of a particular $a$ and a property (as Maurin herself points out, see Maurin 2012, p. 796 \& fn. 8). In fact, Bradley's initial question was how a lump of sugar can "be" white, hard, and sweet, and the possible solution he probes is that the lump can be identified with these three properties related (cf. Maurin 2012, p. 795). Hence, the structural core of the Bradleyian regress is preserved if we define "phenomenal unity in complexity" in terms of instantiations of phenomenal properties, related by a unity relation. Here are phenomenological versions of the premises cited above:

$\left(\mathrm{U}_{\mathrm{PU}}{ }^{\prime}\right)$ : There can be contingent phenomenal unity in phenomenal complexity.

$\left(\mathrm{D}_{\mathrm{PUtruth}}\right)$ : If phenomenological descriptions $<\mathrm{P}>$ and $<\mathrm{Q}>$ have different truthconditions, ${ }^{8}$ then what conscious experience is like for $\langle\mathrm{P}\rangle$ to be true is different from what conscious experience is like for $<\mathrm{Q}>$ to be true.

$\left(\mathrm{D}_{\text {PUmaker }}\right)$ : If experiencing $\mathrm{P}$ is different from experiencing $\mathrm{Q}$, then something must make this difference.

This formulation of the problem of phenomenal unity may seem tedious, but the benefit we get is that we can map possible solutions to Bradley's regress to possible solutions to the dual in a relatively direct way.

\subsection{Possible solutions to Bradley's regress and its phenomenological dual}

Interestingly, it seems the regress only starts under the assumption that there can be contingent unity in complexity (however, see Maurin 2012, p. 805, endn. 7). Otherwise, we can just postulate a necessary connection between F-ness and $a$, i.e., a connecting entity on which F-ness or $a$ depend for their existence. This would entail that the state of affairs $\mathrm{F} a$ always obtains when both F-ness and $a$ exist (because the existence of F-ness and $a$ entails the existence of the connecting entity). In general, this is not plausible, because some entities have (at least some of) their properties contingently. So the question how there can be contingent unity in complexity cannot be avoided. But if we are only interested in a particular type of unity, like phenomenal unity, things may be different. For if we believe that phenomenal unity is a necessary type of unity, it may be that the relata of $\mathrm{R}_{\mathrm{PU}}$ depend for their existence on whatever connecting entity unifies them. The challenge then is to show that there is a special phenomenal property on which all other phenomenal properties depend for their existence (so it must be fundamental in some sense), and to show how that is possible (for a similar remark in the context of Bradley's regress, cf. Gaskin 2008, p. 371). Denote this hypothetical phenomenal property by $\mathrm{F}_{\text {fund }}$.

What could be an example of $\mathrm{F}_{\text {fund }}$ ? A possible candidate is the experienced temporal flow. Recall from above that research on postdictive phenomena suggests

\footnotetext{
${ }^{8}$ Without loss of generality, I am here assuming that $\langle\mathrm{P}\rangle$ and $\langle\mathrm{Q}\rangle$ are hypothetical phenomenological descriptions referring to the same conscious organism at the same time. This excludes the possibility of phenomenological twins, for whom there is no difference in "what it's like", even though the corresponding phenomenological descriptions have different truth conditions. This does not restrict the scope of the argument, because $\mathrm{R}_{\mathrm{PU}}$ is a relation between phenomenal properties instantiated by the same organism.
} 
that events are always experienced as part of a temporal context. A temporal context is something which has temporal parts, and not all of these parts are simultaneous. Hence, even if we do not always experience a determinate temporal order, we experience at least a temporal flow. Is this a single phenomenal property, or can there be different experienced flows? According to Husserl, such flows are always connected:

We find many flows because many series of primal sensations begin and end. But we find a connecting form because the law of the transformation of the now into the no-longer - and, in the other direction, of the not-yet into the now-applies to each of them, but not merely to each of them taken separately; there rather exists something like a common form of the now, a universal and perfect likeness in the mode of flowing. (Husserl 1991, p. 81)

Even if we agree with Husserl that there can be different experienced temporal flows, this does not rule out the possibility that there is still a connecting fundamental phenomenal property: for all experienced time objects at least share a single temporal direction in which they are experienced as unfolding. So the experienced directionality of the flow is unique, and thus constitutes at least a possible candidate for $\mathrm{F}_{\text {fund }}{ }^{9}$

Let me now turn to the possible solutions to the Bradleyian regress considered by Maurin. The first is to argue that there is no regress at all. According to this idea, what unifies the entities involved in a complex state of affairs is akin to glue: glue can connect things, but it does not itself have to be glued (you do not need any super-glue). 10 This is challenged by Vallicella (2002), who points out that the mere existence of glue and of some things that can be glued together does not entail that the glue is actually attached to these things: "[T] he existence of two boards and some glue does not entail the existence of two-boards-glued-together." (2002, p. 207). The only way to save the idea of a metaphysical glue seems to be to assume that the glue depends for its existence on the specific entities it connects (so whenever the glue exists, the entities exist, as well, cf. Maurin 2012, p. 799). The phenomenological dual of this idea is that there is some phenomenal property $\mathrm{F}_{\text {glue }}$ that can only be instantiated if two (or more) specific phenomenal properties are instantiated. So whenever two conscious experiences that display phenomenal unity differ (in terms of their respective phenomenal characters), this means that $\mathrm{F}_{\text {glue }}$ must differ for these two experiences.

Why does $F_{\text {glue }}$ have to be different for different unified conscious experiences? First of all, $F_{\text {glue }}$ must depend for its existence on other phenomenal properties. Otherwise, it does not stop the regress (there would not necessarily be a connection between $\mathrm{F}_{\text {glue }}$ and other phenomenal properties, just as when two boards and some glue exist, but the glue is not attached to the boards). Secondly, assume that $\mathrm{F}_{\text {glue }}$ depends for its existence on either two of the phenomenal properties A, B, and C. So when $\mathrm{F}_{\text {glue }}$ is instantiated, at least two of those properties are also instantiated, say, A\&B (in the board-analogy, this would mean that the glue must be attached to at least two of the boards). The difference between unity ( $\mathrm{A}$ and $\mathrm{B}$ are unified) and disunity ( $\mathrm{A}$ and $\mathrm{B}$ are not unified)

\footnotetext{
${ }^{9}$ Even if you are watching a movie in reverse while listening to someone talking, it is not the case that there are two experienced temporal directions. You just notice that the scenes you are watching are in the reverse order, but the direction of the experienced flow is the same.

${ }^{10}$ As Maurin points out, this suggestion has been made by Reinhardt Grossmann (1983).
} 
would then be the presence of $\mathrm{F}_{\text {glue }}$. But what is the difference between the following three cases: (i) A, B, and $\mathrm{C}$ are disunified. (ii) $\mathrm{A}$ and $\mathrm{B}$ are unified, but neither $\mathrm{A}$ nor $\mathrm{B}$ is unified with $\mathrm{C}$. (ii) $\mathrm{A}, \mathrm{B}$, and $\mathrm{C}$ are unified.

According to the proposal at hand, the difference between (i) and (ii) would be $\mathrm{F}_{\text {glue }}$. But then it seems there is no difference between (ii) and (iii). Of course, it is possible that $\mathrm{A}, \mathrm{B}$, and $\mathrm{C}$ are such that whenever two of them are unified, all three are unified, as well, but there seems to be no reason why this should in general be true for all phenomenal properties. (Just as in the case of three boards, which are not necessarily all glued together when two of them are glued together.) This suggests that $F_{\text {glue }}$ should be different for different groups of phenomenal properties.

What would be an example of a phenomenal property $\mathrm{F}_{\text {glue }}$ ? A possible candidate is the phenomenology of field transitions. In brief, a field transition is a change in the contents of consciousness, where previously unattended items enter the focus of attention. In their discussion of Aron Gurwitsch's field theory of consciousness, Yoshimi \& Vinson (2015) point out that such changes in the contents of consciousness can be variously smooth or jarring, and that how such changes are experienced can depend on what they call the predictive relevance of unattended items:

The predictive relevance between a theme [i.e., the focus of attention] and a peripheral item is (roughly) the probability of transitioning to that peripheral item, given what the current theme is [...]. The more the theme predicts that a given peripheral item will occur next the more predictively relevant that item is to the theme. Peripheral items which are highly predictively relevant to the theme are experienced as a kind of sense of what's coming next, i.e., what Husserl and Gurwitsch called "adumbrations" or "protentions". When adumbrations materialize as expected, experience unfolds in a smooth way. When they fail to materialize as expected, a disruption is experienced. (Yoshimi \& Vinson 2015, p. 117)

So predictive relevance can make an experiential contribution (a "sense of what's coming next"), and it also depends on at least two other phenomenal properties (since it "is (roughly) the probability of transitioning to that peripheral item, given what the current theme is"). Of course, more work would have to be done in order to show how this could form the foundation of an account of phenomenal unity. Here, the purpose of these remarks is only to offer an illustration of how one could make sense of a phenomenal property $\mathrm{F}_{\text {glue }}$.

Another option considered by Maurin is to argue that the regress is not vicious. The truth of $\langle\mathrm{p}>$ entails the truth of $<$ it is true that $\mathrm{p}\rangle$, and the truth of $<$ it is true that it is true that $\mathrm{p}>$ and so on. Similarly, it is the same fact which makes it true that $a$ is $\mathrm{F}$ and that F-ness is connected to $a$ etc. But this does not answer the question: what is it that makes it the case that $a$ is F (cf. Maurin 2012, p. 800)? So this option should be rejected.

Yet another solution is that the regress is positively beneficial: the existence of $\mathrm{F} a$ is explained by the obtaining of the fact that F-ness and $a$ are unified. This, in turn, is explained by the fact that F-ness, $a$, and the unifier are unified, etc. (2012, p. 801). As Maurin points out, this only works under the assumption that explanations do not have to ground out. Furthermore, "[...] you do not get $\mathrm{F} a$ by introducing the regress into an 
F-ness and $a$ world; rather, in order to get the regress, you have to already be in an Fa world." (ibid.).

If we want to apply this solution to PPU, we have to find an analogue to the fact that F-ness and $a$ are unified, and we have to show how the analogue to this fact can account not only for the existence of a phenomenal difference or a unifying moment (in virtue of which the proposition $\left\langle\mathrm{R}_{\mathrm{PU}}(\mathrm{F}, \mathrm{G})>\right.$ is true), but also for the existence of a further unifier (in virtue of which the unifier is unified with $F$ and $G$ ). One option is to argue that $\mathrm{F}$ and $\mathrm{G}$ are dispositionally unified in some sense. This could, for instance, mean that they are jointly cognitively accessible (this is typically called access unity, see Bayne \& Chalmers 2003, p. 29). Examples of joint cognitive access include joint reportability, or being the target of a single cognitive representation (with a content that somehow integrates the contents associated with $\mathrm{F}$ and $\mathrm{G}$, e.g., by subsuming them under a single category etc.). The result of joint cognitive access will often be the existence of a further phenomenal representation (and hence a further phenomenal property). The difference between phenomenal unity and disunity as such is, according to this proposal, not a phenomenal difference, but it goes along with a disposition to instantiate a further phenomenal property (which can then be regarded as "the" phenomenal difference). Crucially, this disposition to cognitively integrate the contents associated with $\mathrm{F}$ and $\mathrm{G}$ (by forming a cognitive representation with associated phenomenal property $\mathrm{H}$ ) may go along with a disposition to cognitively integrate the contents associated with F, G, H, etc.

Other possible solutions to the Bradleyian regress require giving up some assumptions. One assumption is that something must make the difference between unity and disunity. The difference could just be a brute fact (just as the difference between experiencing red and experiencing blue could be taken as a brute fact). A problem with this "solution" is that, pre-theoretically, whatever accounts for phenomenal unity must be something additional. In terms of the single state conception (SSC, see section 4), this can be formulated very clearly: there are not only, say, two phenomenal states $\mathrm{A}$ and $\mathrm{B}$, but there is (in addition) also a phenomenal state $\mathrm{C}$ (of which the first two are a part). So A and B exist both in the case of phenomenal unity, and in the case of disunity. The difference is only that there is an additional state in the case of phenomenal unity.

But there is an alternative way to think about this: when we experience two events together (when we are seeing and hearing a bird, for instance), there is not a phenomenal property corresponding to the visual aspects, and a phenomenal property corresponding to the auditory aspects, but just a phenomenal property corresponding to "visuoauditory" aspects. So according to this proposal, there is no additional phenomenal property, just a different phenomenal property. ${ }^{11}$ This phenomenal property is neither a purely visual phenomenal property, nor a purely auditory phenomenal property, but somehow a fused phenomenal property (just as a perceived sound is a fusion of different features like pitch and loudness). The challenge that comes with this idea is to make it intelligible what a "visuoauditory" aspect is.

Again, taking temporal contexts into account may prove useful. The difference between an experienced succession of events (A-followed-by-B) and a succession of

\footnotetext{
${ }^{11}$ Perhaps Tim Bayne (2010) has something like this in mind when he suggests that "Unity then is not an object of experience but a manner of experiencing." (Bayne 2010, p. 32).
} 
experiences (experiencing first A and then B) might be a difference in which there is nothing which "makes" the difference. Experiencing A-followed-by-B arguably does not involve a phenomenal property corresponding to A, another property corresponding to $\mathrm{B}$, and a third property corresponding to "followed by". Rather, there seems to be more something like an integrated phenomenal property corresponding to the entire succession. The result of this is that attention to particular stages of the process (to one of the experienced events) is required in order to experience them in more detail (just as hearing a chord is best described as an experienced fusion of different notes, although one can attend to individual notes and thus "analyze" the chord). Under the assumption that we always experience events as parts of temporally extended processes, it is plausible that our sense of phenomenal unity is at least considerably shaped by such diachronic unity. As I have argued above, this type of diachronic unity should not be conceptually separated from synchronic phenomenal unity. Furthermore, it is not best construed in terms of an additional phenomenal property (which "makes" the difference), but by positing different phenomenal properties.

Taken together, it seems there are the following possible solutions to the phenomenological dual of Bradley's regress:

1. Identify a fundamental phenomenal property $\mathrm{F}_{\text {fund }}$ on which all other phenomenal properties depend for their existence (example: the directionality of the experienced temporal flow).

2. Identify a class of phenomenal properties $F_{\text {glue }}$ which depend for their existence on other phenomenal properties, such that a difference in the other phenomenal properties goes along with a difference in the gluing property (example: the phenomenology of field transitions).

3. Identify dispositional cognitive states or processes that have the potential to combine different experiential contents. ${ }^{12}$

4. Identify a phenomenal difference without presupposing that there is some (additional) phenomenal property that makes the difference (example: the difference between experiencing first $\mathrm{A}$, and then $\mathrm{B}$, and experiencing A-followed-byB).

These are merely sketches of possible solutions to 1PPU and are therefore mainly intended as suggestions for future research. Given the sketchiness of these proposals, it is likely that proponents of the single state conception (SSC) will not be impressed. In the remainder of this paper, I will show why the above proposals should be taken seriously: we need alternatives to SSC, because SSC does not solve 1PPU.

\section{The single state conception (SSC)}

The basic idea of the common single state conception (SSC) of phenomenal unity is that two events are experienced together just in case the corresponding phenomenal states are both part of a single phenomenal state. For instance, Bayne (2010, pp. 20 f.) "defends a mereological account of phenomenal unity, according to which conscious

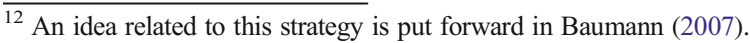


states are phenomenally unified in virtue of the fact that they occur as the parts of a single conscious state."

SSC comes in at least two varieties (unfortunately, many authors fail to specify which type of SSC they are defending). The first stresses the metaphysical aspect of SSC's basic assumption: it emphasizes that phenomenal unity goes along with the existence of a single global conscious state (of which all other conscious states the subject is having at the same time are a part). Note that the mere existence of a global conscious state need not go along with a phenomenal difference, and indeed Tye (2003) defends, as we have seen, a version of SSC according to which PPU is not a phenomenological problem at all. The second type of SSC stresses the phenomenological aspect: it emphasizes that conscious subjects experience a single global conscious state. An example of this idea can be found in the following statement by Giulio Tononi: "Phenomenologically, every experience is an integrated whole [...]." (Tononi 2012, p. 295; emphasis added). Tim Bayne's account meanders a bit between the metaphysical and the phenomenological version. On the one hand, he suggests that phenomenal unity can be characterized in terms of what it is like: "Experiences are phenomenally unified with each other exactly when they exemplify conjoint what-it'slikeness." (Bayne 2014a, p. 522). On the other hand, he states that he is "inclined to think that a case can be made for grounding phenomenal unity in mereological relations." (Bayne 2014a, p. 524). The obtaining of mereological relations between phenomenal states can primarily be regarded as a metaphysical fact; but it can also be regarded as a phenomenological fact if we refer to experienced mereological relations. Given his appeal to "what-it's-likeness", this interpretation actually seems more plausible. ${ }^{13}$ However, Bayne also believes that this has implications for the neural underpinnings of consciousness. This is evidenced by the discussion in Bayne (2010, ch. 10), where he argues that his unity thesis favors a certain type of theory of consciousness (viz. what he calls holistic theories). So according to Bayne, SSC is at least not a purely phenomenological position, but also has metaphysical implications.

This also shows that the distinction between phenomenological and metaphysical SSCs is not exclusive. One can, for instance, first argue that conscious subjects usually have a single conscious state (for instance, in the sense that the physiological underpinnings of the subject's experience form an integrated whole in some sense); in a second step, one can then argue that this unity on the part of the vehicles also goes along with a phenomenal difference (an experience as of a single conscious state). Similarly, one can first argue that there is a lack of vehicle-unity (for instance, in the split-brain-syndrome), and then argue that this goes along with phenomenal disunity. On the other hand, one can also start with a phenomenological claim (conscious subjects experience a single conscious state), and then argue that this has certain implications for the vehicles of consciousness. But it is equally possible to defend an SSC that only involves one of the two aspects (cf. again Tye's account).

\footnotetext{
${ }^{13}$ Cf. also the following statement: "Reflecting on one's consciousness invariably reveals that one enjoys a single phenomenal state that subsumes each of the various experiences that one has at the time in question." Bayne (2014b, p. 489). If this is meant as a phenomenological reflection, then this also indicates that Bayne's account should primarily be considered a phenomenological version of SSC.
} 


\section{SSC creates problems without solving PPU}

In this section, I will highlight three problems created by the single state conception (SSC). I do not claim that these problems cannot be solved; but as long as they remain unsolved they count against the SSC. Hence, if there are alternative conceptions of phenomenal unity that do not face these difficulties, then those should be favored.

These problems mainly arise for the metaphysical SSC, so it might seem that one could avoid them by defending a purely phenomenological SSC. This is a possible strategy. However, it is dialectically weak, for the following reasons. First of all, it is not clear that "being part of the same experience as" is a phenomenally manifest relation (for criticism, see, e.g., Hill 2014, p. 504). Second of all, in order to coherently defend this position, one has to make the assumption that we not only experience objects (or events), but also our experiences themselves. This position has prominent precursors (see, e.g., Brentano 1874, p. 167), but it is also highly controversial (see, e.g., Frank 2002 , ch. VIII). One way to bolster the phenomenological SSC is to complement it with a metaphysical claim, namely that experiencing two (or more) experiences as parts of a common experience goes along with the existence of such a subsuming experience, and that this has implications for the neural underpinnings of consciousness. This strategy has the advantage that it connects the (disputable) phenomenological claim to empirically tractable claims. However, it has the disadvantage that it supports at best a conditional claim of the form: "IF we experience everything as part of a single common experience, THEN the neural underpinnings of consciousness constitute a single neural state." Finding that the neural underpinnings of consciousness constitute a single neural state (or that there is a single consciousness-making mechanism or process in the brain) does not falsify the phenomenological claim, but it does not (uniquely) support it either. For the same prediction can be derived from more conservative phenomenological claims. For instance, if one only assumes that there is a phenomenally manifest unity relation (call it co-consciousness), one can claim that conscious experiences are (metaphysically) unified in virtue of being co-conscious. Adding suitable assumptions about neural underpinnings will then yield the same predictions. The advantage of this strategy is that it does not require making controversial assumptions about consciousness (for instance, that experiences are somehow directed at themselves). The disadvantage is that it does not explicate what the phenomenal contribution of phenomenal unity (co-consciousness) is. Furthermore, it is doubtful that investigating the neural underpinnings of consciousness will tell us anything about the phenomenology of unity - unless we start with phenomenological characterizations of phenomenal unity that are detailed enough as to make specific predictions regarding its neural underpinnings ("detailed enough" here means: more specific than just positing a single neural state or a single consciousness-making mechanism or process - because such claims are compatible with a host of different phenomenological descriptions).

In short: The most straightforward way to complement the phenomenological SSC is via a version of the metaphysical SSC. However, this does not promote progress on PPU as such (because it does not offer a phenomenological characterization of phenomenal unity). Worse, the metaphysical SSC creates problems that are orthogonal to PPU (as I will show in the following paragraphs). Hence, alternatives to the phenomenological SSC (which provide richer phenomenological characterizations) should be sought. 
The problems created by the metaphysical SSC can be formulated in the form of three questions:

1. Can a phenomenal state have phenomenal states as proper parts?

2. Can there be purely subjective individuation criteria for phenomenal states?

3. Can there be purely objective individuation criteria for phenomenal states?

Note that most formulations of SSC suggest a positive answer to the first question, and that they require an answer to the other two questions. If two distinct phenomenal states are phenomenally unified in virtue of being parts of a third phenomenal state (which is distinct from the first two), then this third phenomenal state has proper parts. Furthermore, in order to determine whether two phenomenal states are both parts of a third phenomenal state, we need individuation criteria for phenomenal states. These can be subjective or objective. Subjective criteria are, at least in principle, introspectively accessible. Objective criteria are, at least in principle, accessible from the third-person perspective (for instance, by examining the neural activity in the subject's brain).

My argumentative strategy is not to show that all of these questions have to be answered in the negative. Rather, I shall show that answers to these questions are controversial, and hence problematic. Note that these problems do not arise for the possible solutions to 1PPU suggested in section 3.2.

Ad 1. What reasons are there to deny that phenomenal states can have other phenomenal states as proper parts? This of course depends on what we mean by "parthood". According to some conceptions of parthood, proper parts are independent of the whole in which they occur. This view has been put forward by Andrew Brook. In a review of Bayne's (2010) The Unity of Consciousness, he objects that the multiple phenomenal properties that can be associated with a single phenomenal state are not independent, in the following sense:

Moreover, it is peculiar to call the multiple elements, whatever they are, parts. Unlike normal parts, they cannot exist separately from the whole. They have phenomenality only as aspects of the whole. And so on. Indeed, the element of multiplicity in consciousness is more like events or actions of a system than it is like parts of a system. (Brook 2012, p. 600)

Note that Brook seems to deny that phenomenal states can have any parts whatsoever. A slightly weaker position has been adopted by Tye (2003), who does not deny that phenomenal states can have parts, but only denies that the proper parts of phenomenal states are themselves phenomenal states:

[E]xperiences are, in this way, like statues. Experiences are maximal PANIC states (states having a poised, abstract, nonconceptual content). So, even if some proper parts of experiences are representations, they are not themselves experiences. (Tye 2003, p. 40)

Proponents of SSC have to take a stance regarding these views. Depending on the particular version of SSC one seeks to defend, one will have to endorse or reject Brook's (and / or Tye's) view. It is not possible to merely say that consciousness is 
phenomenally unified just in case there is a single global phenomenal state (which may, or may not, have phenomenal states as proper parts). If one wants to formulate a substantive version of SSC, one also has to provide individuation criteria for phenomenal states (see points 2 and 3 below); otherwise the claim that phenomenal unity involves a global phenomenal state remains empty. SSC thus not only provokes the (controversial) question whether phenomenal states can have phenomenal states as proper parts, but it also demands an answer.

Put differently, proponents of SSC need to take a stance regarding the dispute between what Brook and Raymont (2010) call the "experiential parts theory" (EP) and the "no experiential parts theory" (NEP). Note that in order to defend a version of NEP, one does not have to subscribe to a specific theory of consciousness (like Tye's). ${ }^{14}$ From the point of view of SSC, the dispute between EP and NEP cannot be avoided (it is necessary if one wants to formulate a substantial version of SSC, before one can even begin to try and address 1PPU). However, once SSC is rejected, the debate between EP and NEP becomes a red herring. So proponents of alternatives to the single state conception can just ignore this question.

Ad 2. How do we individuate phenomenal states in the first place? Since SSC connects phenomenal unity to the existence of a single global state, it is plausible to assume that individuation criteria for phenomenal states have to be subjective, at least for versions that acknowledge that it goes along with a phenomenal difference (like Bayne's account). Otherwise, phenomenal unity would not be experientially manifest (the difference between enjoying two separate phenomenal states, and enjoying two states that are part of a single global state, would not be a difference in experience). But then, it would not be phenomenal unity.

Hurley (2003, p. 74) has argued that individuation criteria for phenomenal states have to be (at least partly) objective, because we cannot introspectively distinguish between a case in which one enjoys a single phenomenal state $p$, and a case in which one enjoys two distinct phenomenal states $p_{1}$ and $p_{2}$ of the same type as $p$. If such phenomenal duplicates are possible, it may be that $p_{1}$ and some phenomenal state $q$ are part of a single phenomenal state, but that there is a duplicate, $p_{2}$, that is not part of this phenomenal state. According to SSC, this would be a case of disunity; but if those states are had by the same subject at the same time, it would be introspectively indistinguishable from phenomenal unity. Schechter (2010) defends the view that such duplicates are possible. Proponents of SSC who provide purely subjective individuation criteria for phenomenal states (like Bayne 2014a, p. 522) have to argue against this view. Otherwise, there could be cases of (partial) phenomenal disunity that would not be subjectively distinguishable from cases of phenomenal unity (as long as we hold on to the assumption that phenomenal unity goes along with a phenomenal difference).

A worry that might arise here is that individuation criteria for phenomenal states cannot be purely subjective if we (partly) individuate phenomenal states in terms of the organism which has them. ${ }^{15}$ Or perhaps this criterion is also accessible from the firstperson perspective? Would it make sense to say: "Well, I just experienced a bright flash

\footnotetext{
${ }^{14}$ As Brook and Raymont point out, also William James and John Searle can be regarded as proponents of NEP.

15 Thanks to an anonymous reviewer for pointing this out.
} 
and a loud noise, but I am not sure they were experienced by the same subject."? One could respond that the subject referred to here is the phenomenal subject, which is not identical to the organism. So if neural activity in two distinct organisms can give rise to conscious experiences with a single phenomenal subject (due to some extraordinary connection between the organisms), this might render the subject unable to say if two phenomenal states the subject is experiencing belong to the same organism or not. However, in ordinary cases, the reference to the organism should be less problematic: whenever two or more events are experienced by the same subject at the same time, and when the subject can cognitively access the fact that it consciously experienced these events at the same time, the subject can also access the fact that they were experienced by the same organism. But, even conceding this, the assumption that individuation criteria can be purely subjective is not cut and dried (as illustrated by the hypothetical scenario involving two connected organisms, and the - debatable - possibility of phenomenal duplicates).

Ad 3. Accepting that individuation criteria for phenomenal states have to be (partly) objective seems to be an odd option for proponents of SSC, for the reason just given. If the existence of a single global phenomenal state cannot be detected subjectively in all cases, then there can be cases in which I lack introspective access to the fact that my conscious experience is phenomenally unified (or disunified). But to what extent are we then still talking about phenomenal unity?

Note that being introspectable is a fairly weak requirement on phenomenal unity. It does not presuppose that phenomenal unity makes a positive, additional contribution to phenomenal character, it only presupposes that there is a difference that is brought about by phenomenal unity. Even if we construe phenomenal unity as a relation between phenomenal states, and assume that we cannot directly introspect states, we can still have introspective access to the fact that our phenomenal states are phenomenally unified (this has been pointed out by Bayne 2010, pp. 33 f.).

One option is to postpone the first problem of phenomenal unity (1PPU), and focus on individuation criteria for phenomenal states on subpersonal levels of description. ${ }^{16}$ It has, for instance, been suggested that a single global phenomenal state exists whenever there is a single "consciousness-making mechanism" (CMM) in the subject's brain (cf. O’Brien \& Opie 2000). Theoretical and empirical progress on theories of consciousness may someday reveal how many CMMs there are in the brain, and this will then tell us whether there is a single global phenomenal state or not. Further insights gained by discovering how consciousness is generated in the brain may then also tell what the phenomenal significance of a single global state is, which will in the end vindicate SSC.

Note that this suggestion is highly speculative and also depends on a particular subpersonal account of phenomenal state individuation. At the present, it is impossible to determine how much sense this strategy makes. Hence, alternatives to SSC that do not have to make such speculative assumptions should be preferred over SSC.

\footnotetext{
${ }^{16}$ Elizabeth Schechter seems to suggest a similar strategy: "Given the lack of resolution on whether there might be conscious states that lack phenomenal character, it seems preferable to avoid characterizing coconsciousness in exclusively phenomenological terms, at least for the time being." (Schechter 2013, p. 215, fn. 4).
} 


\section{Why PPU is a difficult problem}

Having argued that SSC is a problematic conception of $\mathrm{R}_{\mathrm{PU}}$, it may now seem rather unattractive, and it may be puzzling why any researchers should adhere to this problematic conception. One reason is that analyzing $R_{\mathrm{PU}}$ is an extremely difficult problem. In this section, I will consider why it is so difficult, hoping that this will make it easier to see how the problems created by SSC can be avoided. In short, the difficulty partly arises from a tension between two putative features of $\mathrm{R}_{\mathrm{PU}}$, which I shall call phenomenality and globality. If we treat both of them as hard constraints on accounts of phenomenal unity, we may never find a solution to PPU. But this does not mean that we have to abandon these constraints completely. Perhaps it suffices to relax them a little. Another source of difficulty is the assumption that consciousness is necessarily unified. I shall discuss this assumption first.

Phenomenal unity is typically considered a necessary feature of consciousness. Hence, contrast methods (cf. Siegel 2007) cannot be used to establish whether $\mathrm{R}_{\mathrm{PU}}$ is experientially manifest, or how it can be characterized phenomenologically. Even if we concede that phenomenal unity is not a necessary feature for all subjects of experience, but only present in neurotypical subjects (a position similar to this is called "biological necessity" by Bayne 2014a, p. 526), this cannot be exploited to establish a phenomenal contrast. For instance, if we believe that split-brain subjects do not enjoy phenomenally unified conscious experiences, this will not facilitate phenomenological characterizations because ordinary subjects do not know "what it's like" to be a split-brain patient. Worse, even split-brain patients themselves do not seem to have experiences of disunity (note that the absence of experiential unity is not necessarily the same as experiencing the absence of unity), so it is not possible to simply ask splitbrain patients to describe what phenomenal disunity is like (cf. also Bayne 2010, p. 218). Hence it seems contrast methods cannot be applied to solve the first problem of phenomenal unity (1PPU).

This is unfortunate, because contrast methods are not even the first choice when it comes to phenomenological characterizations. Contrasts provide indirect characterizations. It would be more desirable to have a direct, positive characterization of phenomenal unity (which should go beyond a mere redescription, or mere re-labeling, as the "conjoint phenomenology" referred to by Bayne \& Chalmers 2003, p. 32). If we cannot provide a direct characterization, it can be helpful to point to examples of unity and disunity, respectively. But if we assume phenomenal unity is in some sense a necessary feature of consciousness, it seems we must restrict ourselves to pointing to examples of unity. In fact, it may seem that this strategy is advisable regardless of whether consciousness is necessarily unified or not. Schechter (2013, p. 199), for instance, suggests this strategy (without endorsing the necessity claim).

As mentioned above, the phenomenality constraint refers to the assumption that phenomenal unity is experientially manifest (which most authors accept). Furthermore, $\mathrm{R}_{\mathrm{PU}}$ is typically construed as a global relation. This means that all phenomenal properties displayed by a subject's conscious experience at a time are phenomenally unified. It is not the case that only all visual aspects of what I 
am experiencing are unified, but all aspects; my entire conscious experience is unified. This is explicit in Bayne's unity thesis: "Let us say that a subject has a unified consciousness if, and only if, every one of their conscious states at the time in question is phenomenally unified with every other conscious state." (Bayne 2010, p. 15).

Now we can see clearly why SSC is so appealing: conceptualizing phenomenal unity in terms of a single global phenomenal state is a very elegant way of satisfying the globality constraint. Furthermore, parthood is a well-known relation that admits of illustrative spatial interpretations. Hence it is intuitive to say that phenomenal states are unified by being part of a single state: it can be imagined as a set diagram in which one set contains several other sets. The mereological relation exemplified by such states is global underlap (two parts underlap just in case there is a third part of which they are both parts, cf. Casati \& Varzi 1999, pp. 36 f.). What makes SSC particularly elegant is that underlap is a relation that can hold between two, but also between more parts; and if there is a single global whole (which has several distinct parts), then all of these parts underlap in virtue of a single part. In other words, there is only a single unifying moment that accounts for phenomenal unity between all phenomenal states. This also takes care of the phenomenological Bradley (at least superficially). For if phenomenal states $E_{1}$ and $E_{2}$ are unified by being parts of $E_{3}$, this third phenomenal state is automatically unified with $E_{1}$ and $E_{2}$, since parthood (in contrast to proper parthood) is a reflexive relation: $E_{1}, E_{2}$, and $E_{3}$, are all parts of a single state, namely $E_{3}$. This seems to solve PB rather elegantly. But it does not solve 1PPU, because we do not get an answer to the question what the phenomenal difference between phenomenal unity and disunity is.

Furthermore, we can also see that phenomenality and globality create a tension. The tension arises because it is difficult to come up with examples of phenomenal unity that are both global and point to experientially manifest features. Consider the following examples given for phenomenal unity:

For example, no matter how hard I try, experiencing the full visual field cannot be reduced into experiencing separately the left half and the right half. No matter how hard I try, I cannot reduce the experience of a red apple into the separate experience of its color and its shape. (Tononi 2012, p. 295)

There is something it is like to hear the rumba, there is something it is like to see the bartender work, and there is something it is like to hear the rumba while seeing the bartender work. (Bayne 2010, pp. $10 \mathrm{f}$.)

When one experiences a noise and, say, a pain, one is not conscious of the noise and then, separately, of the pain. One is conscious of the noise and pain together, as aspects of a single conscious experience. (Brook \& Raymont 2010)

To illustrate: look at your hand and snap your fingers. What happens? You see and feel a movement, and hear a sound. These three experiences - one auditory, one visual and one tactile - do not occur in isolation from one another, they occur 
together within your consciousness, you are aware of them all at once (along with a good deal else). (Dainton 2000, p. xiii)

Note that these are examples of sub-global unity: the first involves only visual aspects, the second only visual and auditory perceptual aspects, the third only audition and nociception, and the fourth auditory, visual, and tactile perception. ${ }^{17}$ Again, if we conceptualize the togetherness of these perceptual events in terms of underlap, it is intuitive to extrapolate from these examples: just add whatever else a subject is currently experiencing, and claim that there is something it is like to experience all of it together.

Note, however, that this diminishes the use of these examples as illustrations of phenomenal unity. Dainton's example already seems to suggest that the only thing phenomenal unity (or co-consciousness, as he calls it) means is that you experience different things "all at once". However, this is clearly not what he intends (because it would trivialize the notion of phenomenal unity). Tononi's examples are more illustrative, because they explicitly characterize (visual) unity: the visual field is a seamless whole that does not seem to have any non-arbitrary parts (apart from visual objects that appear within the visual field); color and shape are necessarily fused (it seems to be impossible to imagine a shapeless color, for instance, even though the shape can be indeterminate or fuzzy). But if we now try to extrapolate from Tononi's examples by adding non-visual aspects, we see that the characterizations do not generalize: tactile aspects of my conscious experience are not seamlessly connected to auditory, visual, or cognitive aspects (at least not in the sense that the halves of the visual field are seamlessly connected, see footnote); and it is easy to imagine a sound without a visual object, or a visual object without a sound. ${ }^{18}$ Perhaps there is another sense in which multimodal experiences are not phenomenologically reducible to their unimodal parts, but the examples given do not provide any insight regarding multimodal cases. ${ }^{19}$

Summing up, the tension between globality and phenomenality consists in the following: on the one hand, examples of phenomenal unity that suggest phenomenological characterizations are sub-global (the characterizations they provide do not

\footnotetext{
${ }^{17}$ In fact, as an anonymous reviewer has pointed out, for a subject whose experience at a time is exhaustingly described by the hearing of the rumba and the seeing of the bartender, the situation described by Bayne would be an example of global unity. But the main point here is that it does not offer an illustration of what the experiential contribution of phenomenal unity is, except for the trivial one that the rumba and the bartender are experienced at the same time.

${ }^{18}$ As an anonymous reviewer rightfully remarked, I do not provide an argument to the effect that, say, auditory and tactile aspects of experience are not seamlessly connected. However, my point here is merely that auditory and tactile aspects are not usually connected in the way in which the two halves of my visual field are connected. Hence, the way in which the parts of the visual field are experienced together cannot function as a model of how all aspects of my experience are experienced together. For instance, I do not experience a boundary between the sides of my visual field when I am staring straight ahead. When I fixate a point on the wall in front of me, it is difficult to tell whether the point is on the left- or on the right-hand side of my visual field. Drawing a sharp boundary between the two halves is experientially arbitrary. By contrast, when I am feeling a pressure on my fingertips, I am not in doubt as to whether this is a visual or a tactile sensation. The distinction between visual and tactile aspects of my experience is (at least) a lot less arbitrary. So if I experience visual and tactile aspects of my experience together (i.e., if they are phenomenally unified), they are not experienced together in the way in which the parts of the visual field or a shape and a color are experienced together. Hence, Tononi's examples do not provide a characterization of global phenomenal unity.

19 Thanks to an anonymous reviewer for pointing this out.
} 
generalize to the entire conscious experience); on the other hand, examples of phenomenal unity that encompass more than strictly local aspects do not suggest interesting phenomenological characterizations (but only characterizations like "all of these events are experienced at once").

\section{Conclusion}

Although the title of this paper may suggest that my aim has been to provide a complete solution to the problem of phenomenal unity, my aim has actually been more modest. I have shown that the problem of phenomenal unity (PPU) can be formulated without making strong metaphysical commitments regarding consciousness as such. A serious challenge for possible solutions to PPU comes from an objection that can usefully be regarded as a phenomenological dual to Bradley's regress, which I call the "phenomenological Bradley" (PB). I have shown how possible solutions to Bradley's regress can inspire possible solutions to $\mathrm{PB}$. These should be taken seriously as alternatives to SSC, because SSC as such does not provide any phenomenological characterizations (and hence does not solve PPU). So if phenomenal unity is conceptualized in terms of SSC, one has to sign an IOU (promising that SSC will somehow enable a phenomenological characterization). SSC has the advantage that it can directly satisfy what I call the globality constraint and that it deals with the phenomenological Bradley rather elegantly. But it creates additional problems (that are orthogonal to PPU as such, see section 5 above). And since the examples of phenomenal unity given by proponents of SSC are strictly sub-global, they are not able to cash the IOU. So, at least at present, SSC can only provide an uncashable IOU and a number of additional problems. Consequently, we should take alternatives to SSC seriously if they sidestep its problems and can provide phenomenological characterizations without IOUs. The only price we may have to pay for this is that the globality constraint may have to be relaxed. But this is a target for future research.

Acknowledgments I am highly grateful to two anonymous referees of this journal for their substantial and constructive feedback. Thanks to the Barbara Wengeler foundation for their generous financial support to cover Springer's open access fee. Part of the work on this paper was supported by a scholarship of the Barbara Wengeler foundation.

Open Access This article is distributed under the terms of the Creative Commons Attribution 4.0 International License (http://creativecommons.org/licenses/by/4.0/), which permits unrestricted use, distribution, and reproduction in any medium, provided you give appropriate credit to the original author(s) and the source, provide a link to the Creative Commons license, and indicate if changes were made.

\section{References}

Baumann, P. (2007). Experiencing things together: what is the problem? Erkenntnis, 66(1), 9-26. doi:10.1007 /s10670-006-9026-x.

Bayne, T. (2005). Divided brains and unified phenomenology: a review essay on Michael Tye's Consciousness and Persons. Philosophical Psychology, 18(4), 495-512.

Bayne, T. (2010). The unity of consciousness. Oxford: Oxford University Press.

Bayne, T. (2014a). Replies to commentators. Analysis, 74(3), 520-529. doi:10.1093/analys/anu066. 
Bayne, T. (2014b). Summary. Analysis, 74(3), 488-490. doi:10.1093/analys/anu054.

Bayne, T., \& Chalmers, D. J. (2003). What is the unity of consciousness? In A. Cleeremans (Ed.), The unity of consciousness: binding, integration, and dissociation (pp. 23-58). Oxford: Oxford University Press.

Bradley, F.H. (1969[1893]). Appearance and reality: a metaphysical essay (2nd ed.). London (a.o.): Oxford University Press.

Brentano, F. (1874). Psychologie vom empirischen Standpunkte. Leipzig: Duncker \& Humblot.

Brook, A. (2012). Review of 'The Unity of Consciousness', by Tim Bayne. Australasian Journal of Philosophy, 90(3), 599-602. doi:10.1080/00048402.2012.671838.

Brook, A., \& Raymont, P. (2010). The unity of consciousness. In E. N. Zalta (Ed.), The Stanford encyclopedia of philosophy (Fall 2010 ed.). Retrieved from http://plato.stanford.edu/archives/fall2010 /entries/consciousness-unity/.

Casati, R., \& Varzi, A. C. (1999). Parts and places: the structures of spatial representation. Cambridge: The MIT Press.

Dainton, B. (2000). Stream of consciousness. unity and continuity in conscious experience. London: Routledge.

Dennett, D. C. (1991). Consciousness explained. New York: Little, Brown, and Co.

Dennett, D. C., \& Akins, K. (2008). Multiple drafts model. Scholarpedia, 3(4), 4321. doi:10.4249 /scholarpedia.4321.

Dennett, D. C., \& Kinsbourne, M. (1992). Time and the observer. Behavioral and Brain Sciences, 15(2), $183-201$.

Eagleman, D., \& Sejnowski, T. (2000). Motion integration and postdiction in visual awareness. Science, 287(5460), 2036-2038.

Fink, S. B. (forthcoming 2016) Why care beyond the square? Shapes of opposition as a tool for discourse analysis. Logica Universalis.

Frank, M. (2002). Selbstgefühl. Eine historisch-systematische Erkundung. Frankfurt a.M.: Suhrkamp.

Gaskin, R. (2008). The unity of the proposition. Oxford: Oxford University Press.

Geldard, F., \& Sherrick, C. (1972). The cutaneous "rabbit": a perceptual illusion. Science, 178(4057), 178-179.

Grossmann, R. (1983). The categorical structure of the world. Bloomington: University of Indiana Press.

Hill, C. S. (1991). Sensations: a defense of type materialism. Cambridge: Cambridge University Press.

Hill, C. S. (2014). Tim Bayne on the unity of consciousness. Analysis, 74(3), 499-509. doi:10.1093 /analys/anu053.

Hurley, S. (2003). Action, the unity of consciousness, and vehicle externalism. In A. Cleeremans (Ed.), The unity of consciousness: binding, integration and dissociation (pp. 72-91). Oxford: Oxford University Press.

Husserl, E. (1991). On the phenomenology of the consciousness of internal time (1893-1917). (Transl. by J. B. Brough.) Dordrecht: Kluwer Academic Publishers.

Masrour, F. (2014). Unity of consciousness: advertisement for a Leibnizian view. In D. J. Bennett \& C. S. Hill (Eds.), Sensory integration and the unity of consciousness (pp. 323-345). Cambridge: The MIT Press.

Maurin, A.-S. (2012). Bradley's regress. Philosophy Compass, 7(11), 794-807. doi:10.1111 /j.17479991.2012.00516.x.

Metzinger, T. (2004[2003]). Being no one: The self-model theory of subjectivity (2nd ed.). Cambridge, MA: The MIT Press.

O’Brien, G., \& Opie, J. (2000). Disunity defended: a reply to Bayne. Australasian Journal of Philosophy, $78(2), 255-263$.

Phillips, I. (2011). Indiscriminability and experience of change. The Philosophical Quarterly, 61(245), 808827. doi:10.1111/j.1467-9213.2011.703.x.

Phillips, I. (2014). The temporal structure of experience. In D. Lloyd \& V. Arstila (Eds.), Subjective time: the philosophy, psychology, and neuroscience of temporality (pp. 139-158). Cambridge: The MIT Press.

Prinz, J. (2012). The conscious brain. How attention engenders experience. Oxford: Oxford University Press.

Schechter, E. (2010). Individuating mental tokens: the split-brain case. Philosophia, 38(1), $195-216$. doi:10.1007/s11406-009-9187-3.

Schechter, E. (2013). Two unities of consciousness. European Journal of Philosophy, 21(2), 197-218. doi:10.1111/j.1468-0378.2010.00439.x.

Shams, L., Kamitani, Y., \& Shimojo, S. (2000). What you see is what you hear. Nature, 408, 788. doi:10.1038 135048669 .

Shimojo, S. (2014). Postdiction: its implications on visual awareness, hindsight, and sense of agency. Frontiers in Psychology, 5(196). doi: 10.3389/fpsyg.2014.00196

Siegel, S. (2007). How can we discover the contents of experience? The Southern Journal of Philosophy, 45(S1), 127-142. doi:10.1111/j.2041-6962.2007.tb00118.x.

Tononi, G. (2012). Integrated information theory of consciousness: an updated account. Archives Italiennes de Biologie, 150, 290-326.

Tye, M. (2003). Consciousness and persons: unity and identity. Cambridge: The MIT Press. 
Vallicella, W. F. (2002). A paradigm theory of existence. Onto-Theology vindicated. Dordrecht: Kluwer Academic Publishers.

Williford, K. (2015). Individuation, integration, and the phenomenological subject. In T. K. Metzinger \& J. M. Windt (Eds.), Open MIND (chap. 39(R)). Frankfurt am Main: MIND Group. doi:10.15502 19783958570771.

Yoshimi, J., \& Vinson, D. W. (2015). Extending Gurwitsch's field theory of consciousness. Consciousness and Cognition, 34, 104-123. doi:10.1016/j.concog.2015.03.017. 